\title{
Esterification over Acid-Treated Mesoporous Carbon Derived from Petroleum Coke
}

\author{
Shida Liu, ${ }^{\dagger}$ Haiyan Wang, ${ }^{\dagger}$ Patrick Neumann, ${ }^{\ddagger}$ Chang Soo Kim, ${ }^{\S}$ and Kevin J. Smith ${ }^{*}{ }^{\dagger}$ \\ ${ }^{\dagger}$ Department of Chemical and Biological Engineering, University of British Columbia, 2360 East Mall, V6T 1Z3 Vancouver, BC, \\ Canada \\ ${ }^{*}$ Department of Chemistry and Catalyst Research Center, Technical University of Munich, Lichtenbergstrasse 4, 85748 Garching, \\ Germany \\ ${ }^{\S}$ Clean Energy Research Center, Korea Institute of Science and Technology, Hwarang-no 14 gil 5, Seongbuk-gu, Seoul 136-791, \\ South Korea
}

\section{Supporting Information}

ABSTRACT: Multistep activation of a Canadian oilsands petroleum coke that yields an acidified mesoporous carbon catalyst is reported. Microporous-activated carbon (APC; $\sim 2000 \mathrm{~m}^{2} / \mathrm{g}$ ), obtained by thermochemical activation of petroleum coke using $\mathrm{KOH}$, was impregnated with ammonium heptamolybdate and activated by carbothermal hydrogen reduction (CHR). The resulting $\mathrm{Mo}_{2} \mathrm{C}$, supported on high-mesopore volume $\left(V_{\text {meso }} \sim 0.4 \mathrm{~cm}^{3} / \mathrm{g}\right)$ carbon, yields the desired mesoporous carbon catalyst $\left(V_{\text {meso }} \sim 0.7 \mathrm{~cm}^{3} / \mathrm{g}\right)$ following acid washing. The effect of CHR temperature and the benefit of $\mathrm{Mo}_{2} \mathrm{C}$ loading on mesopore development is reported, and pore development models are discussed. The mesoporous carbons are active for the esterification of acetic acid and 1-butanol at $77^{\circ} \mathrm{C}$, and the butanol conversion correlates with the catalyst acidity, as measured by $\mathrm{NH}_{3}-\mathrm{TPD}$.

\section{INTRODUCTION}

Bio-oil, as a renewable energy source with the potential to replace some fossil fuels, is one of the most promising products of biomass conversion. ${ }^{1,2}$ However, the properties of bio-oil prevent its direct use in engine combustion. The high oxygen content (35-40\%), low heating value, high acidity, and excessive water content also mean that the bio-oil is unstable during storage. There are several technologies that address these problems, and esterification is one cost effective method that can be used to stabilize bio-oil. ${ }^{3}$ Esterification reduces the polarity of the bio-oil while generating water, and this contributes to an oil-water phase separation and the removal of most of the water from the bio-oil. ${ }^{4,5}$

Esterification reactions are usually catalyzed by homogenous acid catalysts. Despite their high activity and low cost, the environmental impact of waste acid treatment, combined with a difficult catalyst/product separation, means that alternative solid acid catalysts are of interest. ${ }^{6,7}$ Low-cost carbon materials, derived from activated petroleum coke (petcoke) and acidified, have been proposed as potential acid catalysts for esterification. $^{6,7}$

Thermochemical treatment of nonporous petcoke ${ }^{8}$ is used to generate pores and surface area at relatively low activation temperatures $\left(450-900{ }^{\circ} \mathrm{C}\right.$ ) and short activation times. ${ }^{9}$ The activated petcoke may have $\mathrm{O}$ functional groups present on the surface, depending on the activation conditions. The $\mathrm{O}$ functional groups decrease the hydrophobicity of the carbon surface, improving impregnation from aqueous solution when preparing supported metal catalysts. ${ }^{10}$ Furthermore, the functional groups can act as nucleation centers for metallic crystallites, leading to high metal dispersions. ${ }^{11,12}$ These properties suggest the possibility of metal impregnation of activated petcoke to yield highly dispersed metals on the carbon that can then be used in catalytic gasification to generate mesoporous carbons. The catalytic activation of carbonaceous precursors by metals involves reactions similar to those that occur in the catalytic gasification of coal or other carbon-based materials. ${ }^{13,14}$ Transition metals, such as $\mathrm{Ni}, \mathrm{Fe}$, and $\mathrm{Cr}$, are usually applied in coal and carbon gasification processes. $^{15,16}$ However, the aim of catalytic activation is to stop the reaction once a high surface area or pore volume is obtained, without gasifying all of the carbon. As noted by $\mathrm{Wu}$ et al., ${ }^{16} \mathrm{Ni}$ and $\mathrm{Cr}$, initially present in petcoke, can act as catalysts to facilitate activation and pore development. Tomita et al. ${ }^{17}$ reported that the presence of $\mathrm{Ni}$ accelerates the steam gasification of coal mainly by pitting. Metal sites on the carbon act as active sites for the reaction between $\mathrm{C}$ and $\mathrm{H}_{2} \mathrm{O}$ or $\mathrm{CO}_{2}$. To produce mesopores, the required activation temperature is

Received: December 11, 2018

Accepted: March 20, 2019

Published: March 29, 2019 
relatively high, and consequently the carbon yield is low. ${ }^{18,19}$ Recently, the use of carbothermal hydrogen reduction (CHR) to synthesize $\mathrm{Mo}_{2} \mathrm{C}$ catalysts supported on carbon ${ }^{20}$ was shown to also significantly enhance the mesoporosity of the carbon support. ${ }^{21}$

Porous carbon can be functionalized by acid treatment to yield acid catalysts ${ }^{22,23}$ or surface-functionalized materials. ${ }^{24}$ Acid treatment by $\mathrm{H}_{2} \mathrm{SO}_{4}$ or $\mathrm{HNO}_{3}$ is common, ${ }^{24-27}$ and after acid treatment, the carbon can be used as a catalyst support with high concentration of $\mathrm{O}$ functional groups that improve the metal dispersion. ${ }^{27}$ They can also be used directly in esterification reactions as acid catalysts. Liu et al. ${ }^{28}$ reported that $-\mathrm{SO}_{3} \mathrm{H}$-functionalized carbon showed good activity for the esterification of oleic acid and methanol compared with Amberlyst-15. Carbon-based solid acid catalysts were also used by Shu et al. ${ }^{29}$ to convert vegetable oil to fatty acids via hydrolysis.

The aim of the present study is to transform Canadian oilsands petcoke into a valuable mesoporous carbon with sufficient surface acidity so as to be able to act as an esterification catalyst. A multistep approach was used in which thermochemical activation of the petcoke with $\mathrm{KOH}$ was followed by impregnation with ammonium heptamolybdate prior to carbothermal hydrogen reduction (CHR). An acid wash was then used to reduce the Mo content of the carbon and acidify the catalyst surface. The impact of both the Mo loading and the CHR temperature on the carbon porosity is reported, and the benefit of using $\mathrm{Mo}_{2} \mathrm{C}$ in the preparation of the acidified mesoporous carbon is demonstrated. Finally, the catalytic activities of the acidified mesoporous carbons, derived from $\mathrm{Mo}_{2} \mathrm{C} / \mathrm{APC}$ and APC alone, assessed using acetic acid and 1-butanol as model reactants for esterification, are compared.

\section{RESULTS}

The properties of the activated petcoke (APC_800) and the acid-washed APC_800 are summarized in Table 1, together

Table 1. Textural Properties, Acidities, and Reaction Rates of the Raw Petcoke and the Activated Petcoke before (APC_800) and after Acid Treatment (Acid-T APC_800) ${ }^{a}$

$\begin{array}{lllc} & \text { raw petcoke } & \text { APC_800 } & \text { Acid-T APC_800 } \\ \text { surface area, } \mathrm{m}^{2} / \mathrm{g} & 3 & 2037 & 1723 \\ V_{\text {Total }} \mathrm{cm}^{3} / \mathrm{g} & 0.01 & 0.84 & 0.91 \\ V_{\text {meso }}, \mathrm{cm}^{3} / \mathrm{g} & <0.01 & 0.07 & 0.20 \\ \mathrm{NH}_{3} \text { uptake, } \mu \mathrm{mol} / \mathrm{g} & & <10 & 1340 \\ X, \mathrm{~mol} \% & <1 & 29.9 \\ k, \mathrm{~m}^{3} \cdot(\mathrm{mol} \cdot \mathrm{s})^{-1} \times 10^{-9} & & <0.01 & 4.7 \\ \mathrm{TOF}, \mathrm{s}^{-1} \times 10^{-2} & & & 1.5 \\ \text { Raman } \mathrm{I}(\mathrm{D}) / \mathrm{I}(\mathrm{G}) & 1.5 \pm 0.01 & 2.9 \pm 0.1 & \end{array}$

${ }^{a} X$ is mol \% butanol conversion; $k$ is the second-order rate constant derived from butanol conversion; TOF is the turnover frequency based on $\mathrm{NH}_{3}$ uptake.

with the acidity $\left(\mathrm{NH}_{3}\right.$ uptake) and esterification activity of both materials. From these data, one concludes that the APC_800 is microporous with minimal acidity and esterification activity. However, the Raman data (Table 1 and Figure S1) show that the APC_800 has more disorder (i.e., is more amorphous) than the raw petcoke. Following the acid wash, both the mesoporosity (Figure S3) and the acidity of the carbon increased significantly and there was a corresponding increase in the esterification activity of the acid-washed APC_800 (i.e., Acid-T APC_800).

The impact of utilizing $\mathrm{CHR}$ and the synthesis of $\mathrm{Mo}_{2} \mathrm{C}$ to impact the properties of the activated petcoke (APC_800) are shown in the property data of $\mathrm{Mo}_{2} \mathrm{C} / \mathrm{APC}$, prepared at different Mo loadings and CHR temperatures, as summarized in the 3D plots of Figure 1, with the data values of the AHM/ APC precursors and $\mathrm{Mo}_{2} \mathrm{C} / \mathrm{APC}$ provided in Table S2 (Supporting Information). Previously, the effect of CHR temperature at a Mo loading of 10 wt $\%$ was reported ${ }^{21}$ whereas the data reported herein provides information on the interacting effects of Mo loading and CHR temperature on the $\mathrm{Mo}_{2} \mathrm{C}$ synthesis and textural properties of the carbon. The data of Figure 1 show that both surface area and total pore volume of the $\mathrm{Mo}_{2} \mathrm{C} / \mathrm{APC}$ generally decreased with increased $\mathrm{Mo}$ loading, regardless of the CHR temperature (Figure 1a,b). A maximum value occurred at a reduction temperature between 800 and $900{ }^{\circ} \mathrm{C}$ at a low Mo loading ( $\leq 2$ wt \%). The highest surface area was obtained for the $0.5 \mathrm{Mo}_{2} \mathrm{C} / \mathrm{APC} \mathrm{R} 900$ sample. Once the reduction temperature reached $700{ }^{\circ} \mathrm{C}$, the surface area remained relatively high $\left(>1800 \mathrm{~m}^{2} / \mathrm{g}\right)$ with the Mo loading $\leq 2 \mathrm{wt} \%$.

Figure 1c shows that the mesopore volume increased with increased $\mathrm{CHR}$ temperature at each Mo loading, provided the $\mathrm{CHR}$ was conducted at $500-900{ }^{\circ} \mathrm{C}$. Above $900{ }^{\circ} \mathrm{C}$, the mesopore volume decreased. The maximum mesopore volume occurred for the $1 \mathrm{Mo}_{2} \mathrm{C} / \mathrm{APC} \mathrm{R} 900$ sample. The data of Table $\mathrm{S} 2$ show a significant increase in mesopore volume for all $\mathrm{Mo}_{2} \mathrm{C} / \mathrm{APC}$ samples compared to their corresponding precursors. The change in textural properties of the $\mathrm{Mo}_{2} \mathrm{C} /$ $\mathrm{APC}$ is a result of the hydrogenation of carbon, yielding mostly $\mathrm{CH}_{4}$ during $\mathrm{CHR}$. The GC-FID results showing the $\mathrm{CH}_{4}$ concentration profiles during $\mathrm{CHR}$ of the $2 \mathrm{Mo}_{2} \mathrm{C} / \mathrm{APC} \_\mathrm{R} 700$, $5 \mathrm{Mo}_{2} \mathrm{C} / \mathrm{APC} \mathrm{R} 700$, and $10 \mathrm{Mo}_{2} \mathrm{C} / \mathrm{APC}$ R700 samples are reported in Figure S2 (Supporting Information). The $\mathrm{CH}_{4}$ concentration in the $\mathrm{CHR}$ product gas increased as the $\mathrm{CHR}$ temperature increased, but then it decreased once the final temperature was reached. Also, a higher Mo loading resulted in increased carbon hydrogenation, as reflected in the higher $\mathrm{CH}_{4}$ concentration in the $\mathrm{CHR}$ product gas.

Finally, the average particle size of the $\mathrm{Mo}_{2} \mathrm{C}$ present on the $\mathrm{Mo}_{2} \mathrm{C} / \mathrm{APC}$ after CHR is reported in Table 2, on the basis of the log-normal distribution applied to the TEM particle size measurements. The data show that increased Mo loading and/ or increased $\mathrm{CHR}$ temperature increased the average $\mathrm{Mo}_{2} \mathrm{C}$ size of the $\mathrm{Mo}_{2} \mathrm{C} / \mathrm{APC}$ samples.

The physical properties of the acid-treated $\mathrm{Mo}_{2} \mathrm{C} / \mathrm{APC}$ samples are compared to the data of the $\mathrm{Mo}_{2} \mathrm{C} / \mathrm{APC}$ prior to acid treatment in Tables 3 and 4. The data show that the acid wash resulted in 50-70\% Mo removal from the catalysts and there was no significant change in surface area after the acid treatment, except for the $2 \mathrm{Mo}_{2} \mathrm{C} / \mathrm{APC} \mathrm{R} 900$ sample. Generally, the mesopore volume increased after acid treatment for all samples, presumably due to the removal of Mo by the acid. The acid-treated sample Acid $\mathrm{T}-1 \mathrm{Mo}_{2} \mathrm{C} / \mathrm{APC} \mathrm{R} 900$ had the highest $V_{\text {meso }}\left(0.70 \mathrm{~cm}^{3} / \mathrm{g}\right)$ and $V_{\text {Total }}\left(1.59 \mathrm{~cm}^{3} / \mathrm{g}\right)$.

Tables 3 and 4 also summarize the $\mathrm{NH}_{3}$-TPD results of the $\mathrm{Mo}_{2} \mathrm{C} / \mathrm{APC}$ and acid-treated $\mathrm{Mo}_{2} \mathrm{C} / \mathrm{APC}$ samples. As expected, the acid-treated $\mathrm{Mo}_{2} \mathrm{C} / \mathrm{APC}$ samples had significantly higher acidity in all cases except for the Acid- $\mathrm{T} 2 \mathrm{Mo}_{2} \mathrm{C} /$ APC_R900 sample. The Acid-T $1 \mathrm{Mo}_{2} \mathrm{C} / \mathrm{APC}$ R900 sample had the highest number of acid sites $(1942 \mu \mathrm{mol} / \mathrm{g})$. 

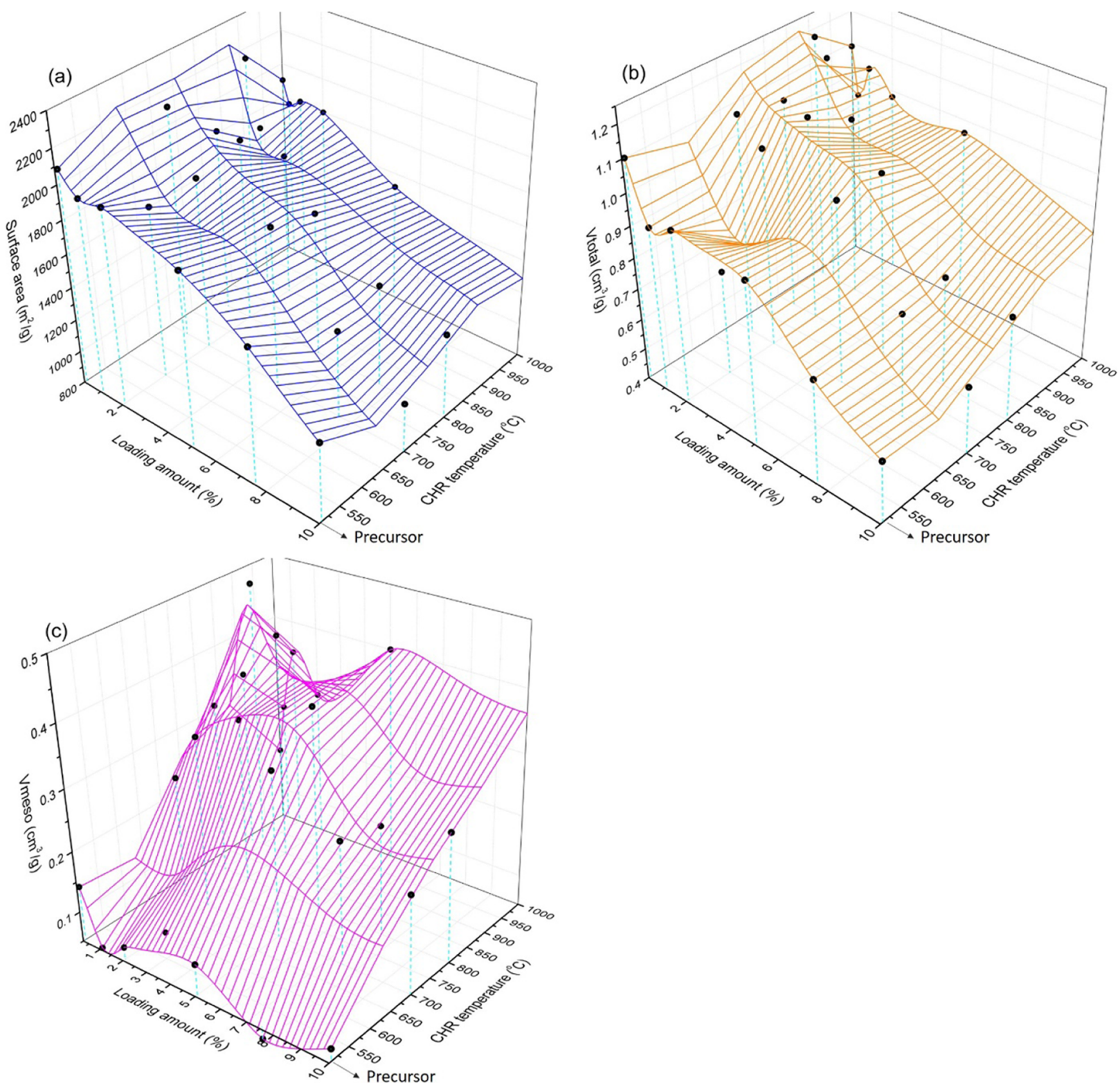

Figure 1. Three-dimensional plot of physical properties of $\mathrm{Mo}_{2} \mathrm{C} / \mathrm{APC}$ samples with various Mo loadings and CHR temperatures: (a) surface area; (b) total pore volume $\left(V_{\text {total }}\right)$; (c) mesopore volume $\left(V_{\text {meso }}\right)$.

1-Butanol and acetic acid were chosen as model reactants to determine the esterification activity of the prepared catalysts. The sole product of the reaction is butyl acetate, and the selectivity was $>99$ wt $\%$ for all tests reported herein. The results of the activity tests at $77^{\circ} \mathrm{C}$ for the APC 800 and acidtreated APC_ 800 are reported in Table 1 , and the $\mathrm{Mo}_{2} \mathrm{C} / \mathrm{APC}$ and acid-treated $\mathrm{Mo}_{2} \mathrm{C} / \mathrm{APC}$ catalysts are compared in Tables 3 and 4. All acid-treated catalysts showed significantly higher conversion than the untreated samples, whereas the acidtreated $\mathrm{Mo}_{2} \mathrm{C} / \mathrm{APC}$ catalysts with a Mo loading $\leq 1 \mathrm{wt} \% \mathrm{had}$ higher activity than that of the acid-treated APC_800 (without Mo). The Acid-T $1 \mathrm{Mo}_{2} \mathrm{C} / \mathrm{APC} \_\mathrm{R} 900$ catalyst had the highest conversion among all samples tested with 52.6\% 1-butanol conversion after $2 \mathrm{~h}$ of reaction. The estimated second-order kinetic rate constants $(k)$, plotted against the number of acid sites as determined by $\mathrm{NH}_{3}$-TPD for both the $\mathrm{Mo}_{2} \mathrm{C} / \mathrm{APC}$ and Acid- $\mathrm{T} \mathrm{Mo}_{2} \mathrm{C} / \mathrm{APC}$ catalysts, are shown in Figure 2. For all $\mathrm{Mo}_{2} \mathrm{C} / \mathrm{APC}$ catalysts without acid treatment, the kinetic constants are approximately constant $(4.9 \pm 0.5) \times 10^{-9} \mathrm{~m}^{3}$. $(\mathrm{mol} \cdot \mathrm{s})^{-1}$, independent of the $\mathrm{Mo}_{2} \mathrm{C}$ loading on the APC. The difference in number of acid sites on these catalysts is relatively small such that the impact on the reaction rate is not evident. However, for the Acid- $\mathrm{T} \mathrm{Mo}_{2} \mathrm{C} / \mathrm{APC}$ catalysts, the kinetic constants clearly increase with the number of acid sites present on the catalyst.

\section{DISCUSSION}

The data of Table 1 show that the activated petcoke is readily converted to an acid catalyst with significant esterification activity following acid washing with fuming $\mathrm{H}_{2} \mathrm{SO}_{4}$. Compared 
Table 2. Particle/Cluster Size of $\mathrm{Mo}_{2} \mathrm{C} / \mathrm{APC}$ Samples with Different Mo Loadings and Different Reduction Temperatures

\begin{tabular}{|c|c|c|c|}
\hline samples & $\begin{array}{c}\text { CHR } \\
\text { temperature, } \\
{ }^{\circ} \mathrm{C}\end{array}$ & $\begin{array}{l}\text { Mo nominal } \\
\text { loading, wt \% }\end{array}$ & $\begin{array}{l}\text { ave. particle } \\
\text { size }(\mathrm{nm})^{a}\end{array}$ \\
\hline $1 \mathrm{Mo}_{2} \mathrm{C} / \mathrm{APC} \_\mathrm{R} 700$ & 700 & 1 & $5.8 \pm 0.3$ \\
\hline $2 \mathrm{Mo}_{2} \mathrm{C} / \mathrm{APC} \_\mathrm{R} 700$ & 700 & 2 & $6.0 \pm 0.2$ \\
\hline $5 \mathrm{Mo}_{2} \mathrm{C} / \mathrm{APC} \_\mathrm{R} 700$ & 700 & 5 & $7.0 \pm 0.4$ \\
\hline $10 \mathrm{Mo}_{2} \mathrm{C} / \mathrm{APC} \_\mathrm{R} 700$ & 700 & 10 & $9.8 \pm 0.7$ \\
\hline $1 \mathrm{Mo}_{2} \mathrm{C} / \mathrm{APC}$ R800 & 800 & 1 & $9.4 \pm 0.2$ \\
\hline $1 \mathrm{Mo}_{2} \mathrm{C} / \mathrm{APC} \_\mathrm{R} 900$ & 900 & 1 & $10.4 \pm 0.2$ \\
\hline $1 \mathrm{Mo}_{2} \mathrm{C} / \mathrm{APC} \_\mathrm{R} 1000$ & 1000 & 1 & $12.6 \pm 0.4$ \\
\hline $0.25 \mathrm{Mo}_{2} \mathrm{C} / \mathrm{APC} \_\mathrm{R} 1000$ & 1000 & 0.25 & $11.4 \pm 0.4$ \\
\hline $0.50 \mathrm{Mo}_{2} \mathrm{C} / \mathrm{APC} \_\mathrm{R} 1000$ & 1000 & 0.5 & $10.3 \pm 0.5$ \\
\hline 2Mo $\mathrm{Mo}_{2} \mathrm{C} / \mathrm{APC} \_\mathrm{R} 1000$ & 1000 & 2 & $22.2 \pm 0.4$ \\
\hline
\end{tabular}

${ }^{a}$ Estimated by analyzing $\geq 100$ particles/clusters and fitting size distribution to a log-normal distribution from which the average particle size was determined.

Table 3. Comparison of $\mathrm{Mo}_{2} \mathrm{C} / \mathrm{APC}$ and Acid-Treated $\mathrm{Mo}_{2} \mathrm{C} / \mathrm{APC}$ Catalysts Prepared at a CHR Temperature of $1000{ }^{\circ} \mathrm{C}$ : Textural Properties, Acidities, and Reaction Rates

\begin{tabular}{lcc} 
& $0.25 \mathrm{Mo}_{2} \mathrm{C} / \mathrm{APC}$ & Acid-T $0.25 \mathrm{Mo}_{2} \mathrm{C} / \mathrm{APC}$ \\
Mo content, wt \% & 0.34 & 0.09 \\
surface area, $\mathrm{m}^{2} / \mathrm{g}$ & 1900 & 1578 \\
$V_{\text {Total }} \mathrm{cm}^{3} / \mathrm{g}$ & 1.09 & 1.32 \\
$V_{\text {meso }} \mathrm{cm}^{3} / \mathrm{g}$ & 0.17 & 0.62 \\
$\mathrm{NH}_{3}$ uptake, $\mu \mathrm{mol} / \mathrm{g}$ & 160 & 1511 \\
$X, \mathrm{~mol} \%$ & 21.2 & 39.9 \\
$k, \mathrm{~m}^{3} \cdot(\mathrm{mol} \cdot \mathrm{s})^{-1} \times 10^{-9}$ & 5.6 & 13.7 \\
$\mathrm{TOF}, \mathrm{s}^{-1} \times 10^{-2}$ & 9.7 & 1.5 \\
\hline
\end{tabular}

to the APC_800 sample, the acid treatment (Acid-T APC 800) increased the porosity of the activated petcoke and generated acid sites on the carbon. The data of Tables 3 and 4 show, however, that the synthesis of $\mathrm{Mo}_{2} \mathrm{C}$ yields $\mathrm{Mo}_{2} \mathrm{C} /$ APC catalysts with significantly higher porosity, acidity and esterification activity after acid treatment when compared to the Acid-T APC_800 (i.e., with no $\mathrm{Mo}_{2} \mathrm{C}$ ).

The textural properties of the $\mathrm{Mo}_{2} \mathrm{C} / \mathrm{APC}$ (Figure 1 and Table S2) reflect the pore enlargement that occurred during the CHR process. As shown in Figures S4 and S5 (Supporting Information), the pore size distributions, calculated using NLDFT, show a shift from micropores to mesopores after $\mathrm{CHR}$ up to a temperature of $900{ }^{\circ} \mathrm{C}$. These data indicate that the micropores are being widened into mesopores during $\mathrm{CHR}$. At a CHR temperature of $1000{ }^{\circ} \mathrm{C}$, an increase in surface area was observed, indicative of new pores being

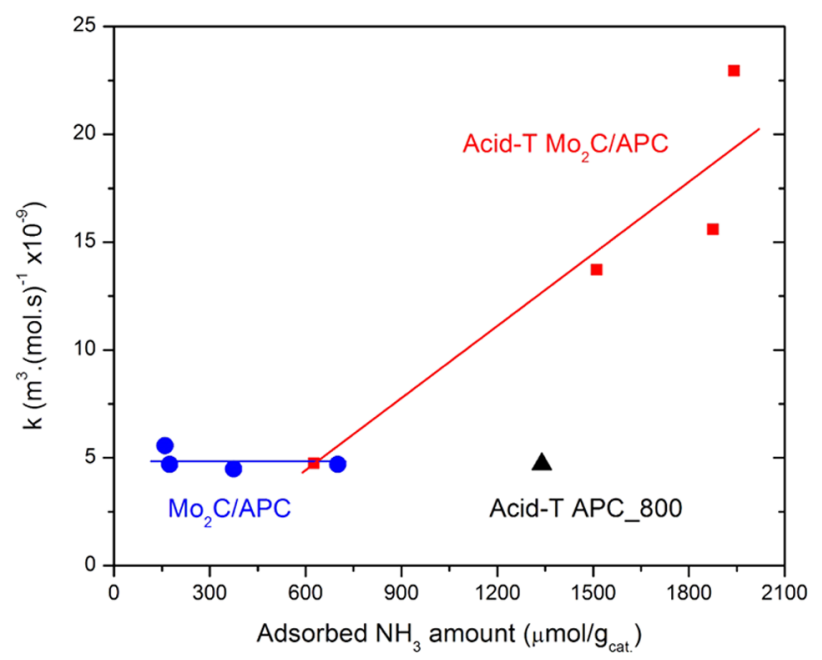

Figure 2. A correlation between adsorbed $\mathrm{NH}_{3}$ and the $2^{\text {nd }}$-order esterification reaction rate constants ( $k$ ): (red $\mathbf{D}$ ) Acid- $\mathrm{T} \mathrm{Mo}_{2} \mathrm{C}$ / APC; (blue - $\mathrm{Mo}_{2} \mathrm{C} / \mathrm{APC}$; (black $\boldsymbol{\Delta}$ ) Acid-T APC_800; trendline .

generated, possibly by pore lengthening. The shape of the isotherms suggest slit-like structures according to the study of Wigmans. ${ }^{30}$ A small loss in mesopore volume also occurred at $1000{ }^{\circ} \mathrm{C}$ due to the high burn-off at this temperature. Hence, two modes of pore development occur during CHR: (i) enlargement of existing pores and (ii) generation of new pores. The widening of an existing pore results in the replacement of the micropore volume with mesopore volume, without significantly increasing surface area. The generation of new pores results in increased surface area, micropore volume and mesopore volume. The latter mode of pore growth, known as channeling, is mainly due to the high crystallinity of graphite, ${ }^{18,31}$ with the size of the resulting pores determined by the particle size of the metal catalyst. ${ }^{31,32}$ Note that the data of Table S3 show that the same CHR treatment up to $800{ }^{\circ} \mathrm{C}$ carried out with the Mo species loaded onto the raw (low surface area) petcoke rather than the APC, did not result in significant increases in surface area or pore volume. This reflects the limited ability of the Mo species to create new pores at the lower CHR temperatures, without some initial porosity generated by the $\mathrm{KOH}$ treatment. The Raman data reported in Table 1 show an increase in the $I(\mathrm{D}) / I(\mathrm{G})$ band intensity ratio after $\mathrm{KOH}$ activation, indicative of an increase in disordered (amorphous) carbon formation following activation. Hence, carbon associated with the pore walls activated during the $\mathrm{KOH}$ treatment will be less crystalline and more reactive than the carbon associated with the original petcoke

Table 4. Comparison of $\mathrm{Mo}_{2} \mathrm{C} / \mathrm{APC}$ and Acid-Treated $\mathrm{Mo}_{2} \mathrm{C} / \mathrm{APC}$ Catalysts Prepared at a CHR Temperature of $900{ }^{\circ} \mathrm{C}$ : Textural Properties, Acidities, and Reaction Rates

\begin{tabular}{|c|c|c|c|c|c|c|}
\hline & $0.5 \mathrm{Mo}_{2} \mathrm{C} / \mathrm{APC}$ & Acid-T $0.5 \mathrm{Mo}_{2} \mathrm{C} / \mathrm{APC}$ & $1 \mathrm{Mo}_{2} \mathrm{C} / \mathrm{APC}$ & Acid-T $1 \mathrm{Mo}_{2} \mathrm{C} / \mathrm{APC}$ & $2 \mathrm{Mo}_{2} \mathrm{C} / \mathrm{APC}$ & Acid-T $2 \mathrm{Mo}_{2} \mathrm{C} / \mathrm{APC}$ \\
\hline Mo content, wt \% & 0.56 & 0.16 & 1.22 & 0.58 & 2.85 & 1.23 \\
\hline surface area, $\mathrm{m}^{2} / \mathrm{g}$ & 2172 & 1823 & 1786 & 1962 & 1673 & 908 \\
\hline$V_{\text {Total }}, \mathrm{cm}^{3} / \mathrm{g}$ & 1.19 & 1.45 & 1.14 & 1.59 & 0.98 & 1.01 \\
\hline$V_{\text {meso }}, \mathrm{cm}^{3} / \mathrm{g}$ & 0.34 & 0.63 & 0.49 & 0.70 & 0.42 & 0.65 \\
\hline $\mathrm{NH}_{3}$ uptake, $\mu \mathrm{mol} / \mathrm{g}$ & 174 & 1876 & 375 & 1942 & 701 & 626 \\
\hline$X, \mathrm{~mol} \%$ & 18.5 & 43.0 & 17.8 & 52.6 & 18.5 & 18.7 \\
\hline$k, \mathrm{~m}^{3} \cdot(\mathrm{mol} \cdot \mathrm{s})^{-1} \times 10^{-9}$ & 4.7 & 15.6 & 4.5 & 22.9 & 4.7 & 4.8 \\
\hline TOF, $\mathrm{s}^{-1} \times 10^{-2}$ & 8.0 & 1.2 & 3.6 & 1.2 & 2.0 & 2.3 \\
\hline
\end{tabular}


that was not activated by the $\mathrm{KOH}$. Consequently, in the initial stage of the catalytic hydrogenation at lower reaction temperatures, amorphous carbon associated with the pore walls is hydrogenated, resulting in the widening of pores. As the amorphous carbon is removed, pore lengthening will also occur as the less reactive, crystalline carbon is hydrogenated at higher temperature. The physical properties of $\mathrm{Mo}_{2} \mathrm{C} / \mathrm{APC}$ generated at temperatures below $900{ }^{\circ} \mathrm{C}$, reflect the pore enlargement that occurred during the $\mathrm{CHR}$ by widening of the micropores present in the APC, rather than through the development of new pores.

The data trends in Figure 1 and Table S2 are consistent with the two pore development modes operating at different temperatures especially at lower Mo loading ( $\leq 2 \mathrm{wt} \%)$. The hydrogenation of amorphous carbon appears to dominate the pore growth mechanism at lower temperatures $\left(\leq 900{ }^{\circ} \mathrm{C}\right)$. From 700 to $900{ }^{\circ} \mathrm{C}$, it can be seen that the mesopore volume steadily increased with a small loss in surface area and micropore volume for the catalysts with 1 and $2 \mathrm{wt} \%$ Mo. The increase in mesopore volume and loss in micropore volume can be explained by the width of pores. Merging of two pores when the wall between them is too thin will result in a loss of surface area. After the amorphous carbon is consumed at lower temperatures, the Mo species react with the highly crystallized carbon. At $1000{ }^{\circ} \mathrm{C}$, surface area and micropore volume increased with loss of mesopore volume as pore lengthening dominates. The loss of mesopores is due to the collapse of pore walls and the loss of the outer surface of the carbon particles at higher temperature. It can be concluded that for the 1 and 2 wt \% Mo loading catalysts, the dominating pore development mechanism shifted from widening to lengthening due to the increase in reduction temperature. A diagram of pore development of $\mathrm{Mo}_{2} \mathrm{C} / \mathrm{APC}$ with different Mo loadings and CHR temperatures is illustrated in Figure 3.

The detailed mechanism of $\mathrm{Mo}_{2} \mathrm{C}$ generation during $\mathrm{CHR}$ has been described elsewhere ${ }^{21}$ for the case of $10 \mathrm{wt} \% \mathrm{Mo}$ loading; whereas, in the present study, different Mo loadings and CHR temperatures were investigated to better understand

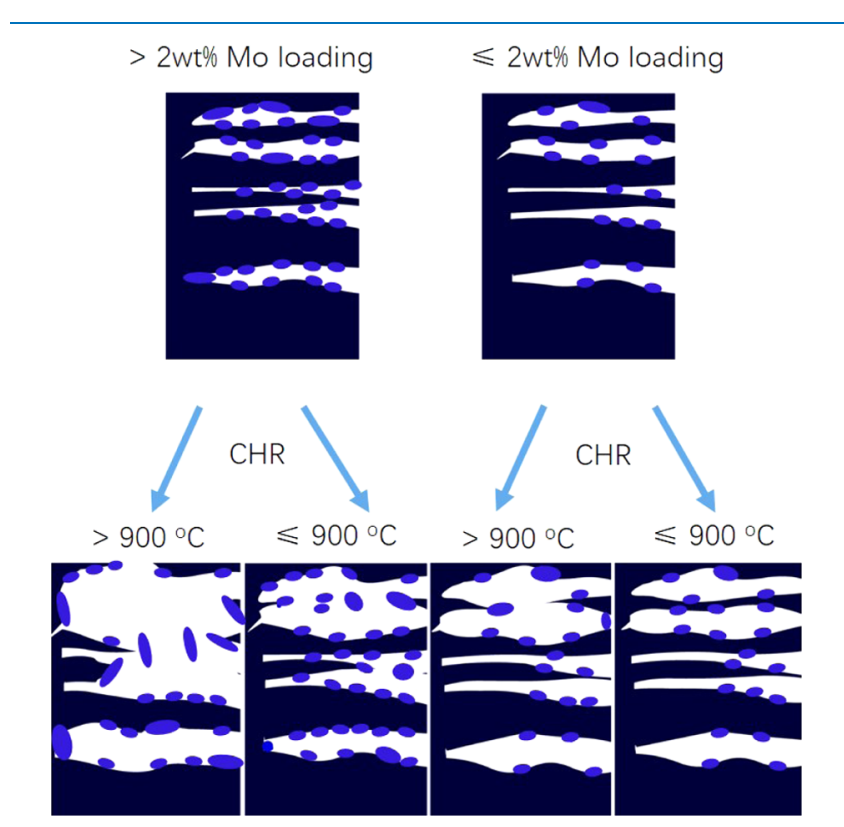

Figure 3. Diagram of pore development process of AHM/APC precursors with different Mo loadings and CHR temperatures. the generation of the mesoporous carbon. The average $\mathrm{Mo}_{2} \mathrm{C}$ particle size, as measured by TEM, increased with increased loading at the same CHR temperature. The phenomenon is common to supported catalysts - at low loading the Mo is well dispersed; whereas, at high loading the proximity of particles on the carbon surface can result in aggregation of smaller particles. Consequently, some of the $\mathrm{Mo}_{2} \mathrm{C}$ or $\mathrm{MoO}_{x} \mathrm{C}_{y}$ particles grow into larger particles. At high temperature $\left(1000{ }^{\circ} \mathrm{C}\right)$, the $\mathrm{Mo}_{2} \mathrm{C}$ or $\mathrm{MoO}_{x} \mathrm{C}_{y}$ become much more mobile on the support surface and there is a higher chance that two or more adjacent particles aggregate upon contact. Alternatively, as the $\mathrm{Mo}_{2} \mathrm{C}$ or $\mathrm{MoO}_{x} \mathrm{C}_{y}$ species consume the carbon support adjacent to the particle during $\mathrm{CHR}$, the particles may contact each other and hence aggregate. Moreover, the consumption of the carbon is determined by the overall contact area between the Mo species and carbon support. For example, total carbon loss per gram of Mo for the $1 \mathrm{Mo}_{2} \mathrm{C} / \mathrm{APC}$ R800 sample ( 40 $\mathrm{gC} / \mathrm{gMo}$ ) with a $\mathrm{Mo}_{2} \mathrm{C}$ particle size of $9.4 \mathrm{~nm}$ (Table 2) is about 5 times that of the $10 \mathrm{Mo}_{2} \mathrm{C} / \mathrm{APC}$ R800 sample (7.5 $\mathrm{gC} / \mathrm{gMo}$ ) with a particle size of $10.8 \mathrm{~nm}$ and the former has $\geq 10$ times the mesopore volume generated on a per gram of Mo basis (calculation details are provided in the Supporting Information). The larger the $\mathrm{Mo}_{2} \mathrm{C}$ particle size, the lower the overall $\mathrm{Mo} /$ carbon contact area, resulting in less efficient pore generation by the Mo. Large particles also create larger pores which have a higher likelihood of collapse with loss of surface area.

The catalysts with low Mo loading ( $\leq 2$ wt \% Mo) and prepared at $\mathrm{CHR}$ temperatures $\geq 900{ }^{\circ} \mathrm{C}$ were selected for acid treatment and the esterification reaction since at higher Mo loading the pore generation efficiency was lower and the resulting materials had fragile pore walls; whereas, at lower CHR temperatures the mesopore volume of the catalyst was relatively low (and similar to that obtained without the Mo see the Acid-T APC_800). As summarized in Tables 3 and 4, acidity was present in both the $\mathrm{Mo}_{2} \mathrm{C} / \mathrm{APC}$ catalysts and the acid-treated catalysts. Although part of the acidity may come from $\mathrm{Mo}_{2} \mathrm{C}$ or $\mathrm{MoO}_{x} \mathrm{C}_{y}$, the low Mo content indicates that the majority of the acid sites result from functionalization of the carbon support. The Raman spectroscopy (Figure S1) and CHNS analysis (Table S4) confirmed that the carbon surface of the APC 800 is functionalized by $\mathrm{O}$ that is known to generate acid sites, as has been reported for graphene oxide. $^{33,34}$ In addition, during activation by $\mathrm{CHR}$, defect sites form on the carbon surface as $\mathrm{CH}_{4}$ is generated and these sites can combine with oxygen during passivation. Hence, with increased Mo loading, more defect sites will form, resulting in an increase in acid sites (Tables 3 and 4). From the esterification results we conclude that without acid treatment, the esterification ability of the $\mathrm{Mo}_{2} \mathrm{C} / \mathrm{APC}$ is relatively low, but after acid treatment the catalysts have esterification activity comparable to traditional solid acid catalysts operated at similar temperature. For example, the second-order rate constants $(k)$ of the $1 \mathrm{Mo}_{2} \mathrm{C} / \mathrm{APC} \mathrm{R} 900$ and the Acid-T $1 \mathrm{Mo}_{2} \mathrm{C} / \mathrm{APC} \mathrm{R} 900$ measured at $77^{\circ} \mathrm{C}$ were $0.5 \times 10^{-8} \mathrm{~m}^{3}$. $(\mathrm{mol} \cdot \mathrm{s})^{-1}$ and $2.3 \times 10^{-8} \mathrm{~m}^{3} \cdot(\mathrm{mol} \cdot \mathrm{s})^{-1}$, respectively. These values compare favorably with the ion-exchange catalysts reported by Peters et al. ${ }^{35}$ for the same reaction operated at 75 ${ }^{\circ} \mathrm{C}$. Analyzing their data ${ }^{35}$ using the same methodology as for the $\mathrm{Mo}_{2} \mathrm{C} / \mathrm{APC}$ catalysts (see Section 5.4), values of $2.1 \times$ $10^{-8} \mathrm{~m}^{3} \cdot(\mathrm{mol} \cdot \mathrm{s})^{-1}$ and $2.7 \times 10^{-8} \mathrm{~m}^{3} \cdot(\mathrm{mol} \cdot \mathrm{s})^{-1}$ for Amberlyst15 and Smopex-101 catalysts, were obtained, respectively. 
After acid treatment, the textural properties of catalysts were significantly improved (Tables 1, 3, and 4). Comparing the APC_ 800 and acid-treated APC_ 800 shows that the acid treatment resulted in increased porosity and acidity of the carbon. The acid treatment also removed $>50 \%$ of Mo from the pores of the $\mathrm{Mo}_{2} \mathrm{C} / \mathrm{APC}$ samples, further increasing the mesoporosity of the catalyst. More importantly, the acid treatment introduces oxygen functional groups such as $-\mathrm{SO}_{3} \mathrm{H}$ and $-\mathrm{COOH}$ onto the catalyst surface. ${ }^{2,23}$ The increase in $\mathrm{S}$ content of the Acid-T APC_800 compared to the APC 800 sample (Table S5) indicates the presence of $-\mathrm{SO}_{3} \mathrm{H}$. However, with a $S$ content of only $0.2 \mathrm{wt} \%$ on the Acid-T APC 800 sample, the corresponding $-\mathrm{SO}_{3} \mathrm{H}$ content of the catalyst is approximately $63 \mu \mathrm{mol} / \mathrm{g}$. Since this is significantly lower than the acidity determined from $\mathrm{NH}_{3}$ TPD (Table 1), we conclude that most of acidity arises from other oxygen functional groups on the acid-treated carbon surface, such as -COOH. Consequently, most of the acid-washed catalysts had higher acidity and higher esterification activity per gram of catalyst than the corresponding $\mathrm{Mo}_{2} \mathrm{C} / \mathrm{APC}$. In one case, the $2 \mathrm{Mo}_{2} \mathrm{C} /$ APC_R900 catalyst loses significant surface area after the acid treatment, presumably due to loss of pore walls. As Figure 3 shows, the second-order rate constant increased with increased acidity of the acid-treated $\mathrm{Mo}_{2} \mathrm{C} / \mathrm{APC}$ catalysts. Assuming that the $\mathrm{NH}_{3}$ uptake is a measure of the number of active sites of the acid-treated catalysts, the turnover frequency (TOF) was calculated for each catalyst and is reported in Tables 1,3 , and 4. We note that the acid-treated catalysts have similar TOFs, as expected from Figure 2 that shows an approximate linear increase in the second-order rate constant with $\mathrm{NH}_{3}$ uptake. Hence, we conclude that the same type of acid sites $\left(-\mathrm{SO}_{3} \mathrm{H}\right.$ and $-\mathrm{COOH}$ ) are mostly responsible for the esterification reaction on all acid-washed catalysts. For the nonacid-washed $\mathrm{Mo}_{2} \mathrm{C} / \mathrm{APC}$ catalysts, the $\mathrm{NH}_{3}$ uptake was significantly lower than that for the acid-treated catalysts. The $\mathrm{NH}_{3}$ must titrate acid sites associated not with the acid washing $\left(-\mathrm{SO}_{3} \mathrm{H}\right.$ or $-\mathrm{COOH}$ acid sites) but rather those associated with $\mathrm{O}$ species of the $\mathrm{Mo}_{2} \mathrm{C}$ and the activated carbon. ${ }^{36}$ The $\mathrm{NH}_{3}$ uptake increased with increased $\mathrm{Mo}_{2} \mathrm{C}$ content, and the corresponding TOF of the nonacid-washed $\mathrm{Mo}_{2} \mathrm{C} / \mathrm{APC}$ catalysts generally decreased as the $\mathrm{Mo}_{2} \mathrm{C}$ loading increased. In this case, many factors may impact the calculated TOF, including a change in the type of sites as the Mo loading increased, increased mesoporosity, and lower $\mathrm{Mo}_{2} \mathrm{C}$ dispersion. Hence, the TOFs of the nonacid-treated samples cannot be compared directly to those of the acid-treated samples nor can they be compared directly to one another since the type of acid site is changing (Mo oxycarbide versus $\mathrm{O}$ functional group on the carbon), the $\mathrm{Mo}_{2} \mathrm{C}$ dispersion is decreasing, and the internal mass transfer to the acid sites is increasing as the Mo loading increases. The Acid-T $1 \mathrm{Mo}_{2} \mathrm{C} / \mathrm{APC} \_\mathrm{R} 900$ had the highest acidity among all catalysts and had about two times higher activity than that of the acid-treated APC_800 catalyst (with no Mo) and the $\mathrm{Mo}_{2} \mathrm{C} / \mathrm{APC}$ catalyst that were not acid-washed.

\section{CONCLUSIONS}

High-surface area microporous carbons (APC) were prepared from a Canadian oilsands-derived petcoke by thermochemical activation at $800{ }^{\circ} \mathrm{C}$ in the presence of $\mathrm{KOH}$. The subsequent impregnation of the APC with ammonium heptamolybdate and activation by carbothermal hydrogen reduction yields $\mathrm{Mo}_{2} \mathrm{C}$ supported on a mesoporous carbon with a high mesopore volume $\left(V_{\text {meso }} \sim 0.4 \mathrm{~cm}^{3} / \mathrm{g}\right)$. Mesoporous carbons
( $V_{\text {meso }} \sim 0.7 \mathrm{~cm}^{3} / \mathrm{g}$ ) were subsequently obtained by acid washing. Both CHR temperature and Mo loading impact the textural properties of the carbons. Acid treatment significantly improves the catalyst activity for all catalysts. The esterification activity of the acid-washed $\mathrm{Mo}_{2} \mathrm{C} / \mathrm{APC}$ catalysts was significantly higher than that of the APC without the Mo. The acid-washed $\mathrm{Mo}_{2} \mathrm{C} / \mathrm{APC}$ prepared with low Mo loading and $\mathrm{CHR}$ temperature up to $900{ }^{\circ} \mathrm{C}$ yields acidic mesoporous carbon with the highest mesoporosity, acidity, and catalyst esterification activity.

\section{EXPERIMENTAL SECTION}

5.1. Raw Materials. Petroleum coke (PC) recovered from a delayed coker was provided by Suncor Energy Inc. The PC was ground and sieved to $90-180 \mu \mathrm{m}$ and then dried overnight at $110{ }^{\circ} \mathrm{C}$ before use. The ultimate analysis of the received material is reported in Table $\mathrm{S} 1$ (Supporting Information). Ammonium heptamolybdate tetrahydrate (AHM; $\left.\left(\mathrm{NH}_{4}\right)_{6} \mathrm{Mo}_{7} \mathrm{O}_{24} \cdot 4 \mathrm{H}_{2} \mathrm{O}\right)$ was used as the Mo precursor. The reactants 1-butanol (Aldrich, 99.9\%) and acetic acid (Aldrich, 99\%) were used as received for the esterification reaction.

5.2. Preparation of APC, AHM/APC, and $\mathrm{Mo}_{2} \mathrm{C} / \mathrm{APC}$. About $3.5 \mathrm{~g}$ of the raw petcoke (BET area: $\sim 3 \mathrm{~m}^{2} / \mathrm{g}$ and pore volume: $\left.\sim 0.01 \mathrm{~cm}^{3} / \mathrm{g}\right)^{37}$ was dry mixed with $\mathrm{KOH}$ in a $\mathrm{KOH} /$ petcoke mass ratio of $3: 1$ and activated in a $\mathrm{N}_{2}$ flow (200 $\mathrm{mL}(\mathrm{STP}) / \mathrm{min}$ ) while heating in a tube furnace at a ramp rate of $5{ }^{\circ} \mathrm{C} / \mathrm{min}$ to the final temperature of $800{ }^{\circ} \mathrm{C}$ and then holding this temperature for $2 \mathrm{~h}$. After cooling to room temperature, the sample was washed with $1 \mathrm{M} \mathrm{HCl}$ solution to remove excess $\mathrm{KOH}$ and then dried at $110{ }^{\circ} \mathrm{C}$ for $8 \mathrm{~h}$. The obtained activated petcoke was designated as APC_800.

The APC 800 sample was then wet-impregnated with ammonium heptamolybdate (AHM) prepared in a 1:9 mass ratio of acetone and deionized water. For lower Mo loadings ( $\leq 2$ wt $\%)$, ca. $3.5 \mathrm{~mL}_{\text {solution }} / \mathrm{g}_{\mathrm{APC}}$ was used for the wet impregnation and for higher Mo loadings (>2.0 wt \%), 5.0 $\mathrm{mL}_{\text {solution }} / \mathrm{g}_{\mathrm{APC}}$ was used for the impregnation. After impregnation, the samples were stabilized at room temperature for 3$4 \mathrm{~h}$ prior to drying at $110{ }^{\circ} \mathrm{C}$ overnight. The AHM/APC precursors were then carbothermally reduced under continuous $\mathrm{H}_{2}$ flow $(100 \mathrm{~mL}(\mathrm{STP}) / \mathrm{min})$ at a designated temperature in a fixed-bed quartz microreactor to convert the AHM to $\mathrm{Mo}_{2} \mathrm{C}$. ${ }^{38}$ The temperature was increased from room temperature to the final temperature $\left(600-1100{ }^{\circ} \mathrm{C}\right)$ at a ramp rate of $1{ }^{\circ} \mathrm{C} / \mathrm{min}$. The final temperature was held for a further $90 \mathrm{~min}$ before switching to a $\mathrm{N}_{2}$ flow $(50 \mathrm{~mL}(\mathrm{STP}) / \mathrm{min})$ and quenching the sample to room temperature. A GC-FID was connected to the outlet of the CHR microreactor to quantify the $\mathrm{CH}_{4}$ produced during the $\mathrm{CHR}$ process. The acquired samples were named as $\mathrm{xxMo}_{2} \mathrm{C} / \mathrm{APC}$ Ryyy, where $\mathrm{xx}$ represents the Mo loading and yyy is the final reduction temperature $\left({ }^{\circ} \mathrm{C}\right)$ of the $\mathrm{CHR}$.

Several samples were subsequently acid-washed to remove Mo. Accordingly, $10 \mathrm{~mL}$ of fuming sulfuric acid (50 wt \% $\mathrm{SO}_{3}$ ) was placed in a $50 \mathrm{~mL}$ round bottom flask and heated to $80^{\circ} \mathrm{C}$ using a heating mantle. The selected $\mathrm{Mo}_{2} \mathrm{C} / \mathrm{APC}$ sample $(0.5$ g) was added to the flask and reacted at $80{ }^{\circ} \mathrm{C}$ for $4 \mathrm{~h}$ under reflux and mixing using a magnetic stirrer. After cooling to room temperature, the acquired mixture was diluted with distilled water. The solid was recovered by filtration after washing with distilled water and dried in an oven for $12 \mathrm{~h}$ before use. The collected samples are identified as Acid-T 
$\mathrm{xxMo}_{2} \mathrm{C} / \mathrm{APC}$ Ryyy. An acid wash of the APC 800 (without $\mathrm{Mo}_{2} \mathrm{C}$ ) was done similarly to determine the impact of Mo on the acid-treated carbon catalysts.

The carbon loss during the CHR process is defined as

$$
\text { burn off }(\%)=\left[1-\frac{m_{\mathrm{Mo}_{2} \mathrm{C}}}{m_{\mathrm{AHM}}}\right] \times 100
$$

where $m_{\mathrm{AHM}}$ is the initial mass of AHM/APC precursor and $m_{\mathrm{Mo}_{2} \mathrm{C}}$ is the final mass of the $\mathrm{Mo}_{2} \mathrm{C} / \mathrm{APC}$ catalyst. The final yield of $\mathrm{Mo}_{2} \mathrm{C} / \mathrm{APC}$ was calculated as follows

$$
\begin{aligned}
& \text { Yield } \mathrm{Mo}_{2} \mathrm{C} / \mathrm{APC}(\%) \\
& =((100-\text { burn off } \%) \times(\mathrm{APC} \text { yield } \%)) / 100
\end{aligned}
$$

5.3. Characterization of $\mathrm{APC}, \mathrm{Mo}_{2} \mathrm{C} / \mathrm{APC}$, and AcidTreated $\mathrm{Mo}_{2} \mathrm{C} / \mathrm{APC}$. $\mathrm{N}_{2}$ physisorption isotherms of the prepared samples were measured at $-196{ }^{\circ} \mathrm{C}$ using a Micromeritics ASAP 2020 analyzer to determine surface area, pore volume, and pore size distribution. Prior to the analysis, $\sim 0.1$ g of the sample was degassed at $200{ }^{\circ} \mathrm{C}(100 \mathrm{~mm} \mathrm{Hg})$ for $4 \mathrm{~h}$. The pore size distribution was calculated by the nonlocal density functional theory (NLDFT) based on a $\mathrm{N}_{2}$ DFT model assuming a pore slit geometry, which is common for carbon materials. The surface area was calculated from the adsorption isotherm in the relative pressure range $\left(p / p_{\mathrm{o}}\right)$ of $0.01-0.30$ using the 2D-NLDFT method. The pore volumes were obtained using the 2D-NLDFT method as well.

The particle size of $\mathrm{Mo}_{2} \mathrm{C}$ on $\mathrm{Mo}_{2} \mathrm{C} / \mathrm{APC}$ was determined from transmission electron microscopy analysis (TEM, FEI Tecnai Osiris operated at $200 \mathrm{kV}$ with a resolution limit of 1.4 $\AA$ ). The presence of certain crystal phases was confirmed by dspacing measurement. The samples were ground to a fine powder and dispersed in ethanol by sonication. One or two drops of the suspension were placed on a 300-mesh lacey carbon film. The TEM images were analyzed and $>100$ particles measured to determine a particle size distribution that was fitted to a log-normal distribution from which the average size of the metal clusters/particles was estimated.

The ultimate analysis of petcoke was conducted in an elemental analyzer (Perkin-Elmer 2400 series II CHNS/O) at a combustion temperature of $975{ }^{\circ} \mathrm{C}$. Elemental analysis of the samples was conducted by inductively coupled plasma optical emission spectroscopy (ICP-OES). All samples were aciddigested in aqua regia at $110{ }^{\circ} \mathrm{C}$ to extract the metals from the support prior to the analysis. Ammonium temperatureprogrammed desorption ( $\left.\mathrm{NH}_{3}-\mathrm{TPD}\right)$ was used to determine the acidity of both $\mathrm{Mo}_{2} \mathrm{C} / \mathrm{APC}$ and the corresponding acidtreated samples. The $\mathrm{NH}_{3}$ desorption was measured using the TCD detector of a Micromeritics AutoChem 2920 unit. The sample was treated in 15 vol $\% \mathrm{NH}_{3}$ under a He flow of 50 $\mathrm{mL}(\mathrm{STP}) / \mathrm{min}$ at $70{ }^{\circ} \mathrm{C}$ for $60 \mathrm{~min}$, followed by flushing in pure $\mathrm{He}$ for $2 \mathrm{~h}$ at the same temperature to remove physisorbed $\mathrm{NH}_{3}$ species. The TPD signal was collected as the sample was subsequently heated under the same $\mathrm{He}$ flow from 100 to $550{ }^{\circ} \mathrm{C}$ at a ramp rate of $10{ }^{\circ} \mathrm{C} / \mathrm{min}$, holding the final temperature of $550{ }^{\circ} \mathrm{C}$ for $30 \mathrm{~min}$.

Horiba Jobin Yvon LabRAM HR800 operated at a laser power of $10 \mathrm{~mW}$, a grating of $1800 \mathrm{~g} / \mathrm{m}$, resolution of 0.65 $\mathrm{cm}^{-1}$, and laser wave length of $532 \mathrm{~nm}$ were used for Raman analysis of the carbons. The samples were analyzed without any pretreatment. The analysis was used to determine the degree of disorder of the synthesized carbon materials by comparing the peak area of the disordered carbon $(I(D))$ to graphitic carbon $(I(G))$. The Raman spectra peak intensity ratio $I(D) / I(G)$ was calculated, where $I(D)$ is the intensity of the $\mathrm{D}$ band peak at $1600 \mathrm{~cm}^{-1}$ and $I(\mathrm{G})$ is the peak intensity of the $\mathrm{G}$ band at $1350 \mathrm{~cm}^{-1}$.

5.4. Catalytic Performance Test of $\mathrm{Mo}_{2} \mathrm{C} / \mathrm{APC}$ and Acid-Treated $\mathrm{Mo}_{2} \mathrm{C} / \mathrm{APC}$. The $\mathrm{Mo}_{2} \mathrm{C} / \mathrm{APC}$ and the corresponding acid-treated samples were assessed for esterification using the model reactants acetic acid and 1-butanol at a mole ratio of $1: 1$ reacted at $77^{\circ} \mathrm{C}$ for $2 \mathrm{~h}$ in a stirred batch reactor under a $\mathrm{N}_{2}$ atmosphere. ${ }^{39}$ The catalysts $0.25 \mathrm{Mo}_{2} \mathrm{C} /$ APC_R1000, $0.50 \mathrm{Mo}_{2} \mathrm{C} / \mathrm{APC}$ R900, $1 \mathrm{Mo}_{2} \mathrm{C} / \mathrm{APC} R 900$, $2 \mathrm{Mo}_{2} \mathrm{C} / \mathrm{APC} \_\mathrm{R} 900$, and APC_ 800 were assessed together with their corresponding acid-treated samples. In each case, the same amount of catalyst was used (ca. $0.2 \mathrm{~g}$ ) and the reactor liquid volume was held constant at $20 \mathrm{~mL}$. After the reaction, the liquid product was separated from the catalyst by a centrifuge and diluted 50 times in acetone prior to quantitative analysis using Shimadzu (QP-2010-S) GC-MS and a Restek RTX5 $30 \mathrm{~m} \times 0.25 \mathrm{~mm}$ capillary column. The conversion of 1 butanol after $2 \mathrm{~h}$ was taken as a measure of catalyst activity. Repeat experiments showed that the measurement error associated with the conversion was $\pm 5 \%$ of the measured conversion. The esterification reaction was assumed to proceed through a second-order reaction with the reaction rate ${ }^{40}$ given by: $r\left(\mathrm{~mol} \cdot \mathrm{gcat}^{-1} \cdot \mathrm{s}^{-1}\right)=k^{*} C_{\mathrm{A}} C_{\mathrm{B}}$ where $C_{\mathrm{A}}$ is the butanol concentration and $C_{B}$, the acetic acid concentration. Assuming a perfectly mixed phase inside the reactor volume and writing the component concentrations in terms of butanol conversion $X$, one obtains the equation: $\mathrm{d} X / \mathrm{d} t=-k C_{\mathrm{A} 0}(1-X)^{2}$ with $k=$ $k^{*} C_{\text {cat }}$ where $C_{\text {cat }}$ is the catalyst concentration in the mixed reactor and $C_{\mathrm{A} 0}$ is the initial concentration of butanol. Hence the second-order rate constant $k$ is determined from the equation $k=X^{*}\left[C_{\mathrm{A} 0} t(1-X)\right]^{-1}$ and the butanol conversion data. ${ }^{41}$ Finally, the catalyst turnover frequency (TOF) was estimated by dividing the rate $r$ measured at the conversion $X$ by the $\mathrm{NH}_{3}$ uptake.

\section{ASSOCIATED CONTENT}

\section{Supporting Information}

The Supporting Information is available free of charge on the ACS Publications website at DOI: 10.1021/acsomega.8b03472.

Ultimate analysis of raw petroleum coke; physical properties of $\mathrm{Mo}_{2} \mathrm{C} / \mathrm{APC}$ with various Mo loadings and $\mathrm{CHR}$ temperatures; textural properties of $\mathrm{Mo}_{2} \mathrm{C} / \mathrm{PC}$ catalysts; Raman analysis of Raw petcoke and APC_800; profile of $\mathrm{CH}_{4}(\mathrm{~mol} \%)$ produced during carbothermal hydrogen reduction (CHR); and NLDFT pore size distributions derived from $\mathrm{N}_{2}$ adsorption isotherms for $1 \mathrm{Mo}_{2} \mathrm{C} / \mathrm{APC}$ and $2 \mathrm{Mo}_{2} \mathrm{C} / \mathrm{APC}$ at different $\mathrm{CHR}$ temperatures (PDF)

\section{AUTHOR INFORMATION}

\section{Corresponding Author}

*E-mail: kjs@mail.ubc.ca. Tel.: +1 6048223601. Fax: +1 6048226003.

ORCID

Kevin J. Smith: 0000-0001-6008-0223

Notes

The authors declare no competing financial interest. 


\section{ACKNOWLEDGMENTS}

This work was supported by the Natural Sciences and Engineering Research Council of Canada (NSERC) and Korea Institute of Science and Technology (KIST)-UBC Biorefinery on-site laboratory program.

\section{REFERENCES}

(1) Xiu, S.; Shahbazi, A. Bio-oil production and upgrading research: A review. Renewable Sustainable Energy Rev. 2012, 16, 4406-4414.

(2) Mohan, D.; Pittman, C. U.; Steele, P. H. Pyrolysis of wood/ biomass for bio-oil: a critical review. Energy Fuels 2006, 20, 848-889.

(3) Zhang, Q.; Chang, J.; Wang, T.; Xu, Y. Review of biomass pyrolysis oil properties and upgrading research. Energy Convers. Manage. 2007, 48, 87-92.

(4) Tang, Y.; Yu, W.; Mo, L.; Lou, H.; Zheng, X. One-step hydrogenation - esterification of aldehyde and acid to ester over bifunctional Pt catalysts: A model reaction as novel route for catalytic upgrading of fast pyrolysis bio-oil. Energy Fuels 2008, 22, 3484-3488.

(5) Wang, J.-J.; Chang, J.; Fan, J. Upgrading of bio-oil by catalytic esterification and determination of acid number for evaluating esterification degree. Energy Fuels 2010, 24, 3251-3255.

(6) Hita, I.; Palos, R.; Arandes, J. M.; Hill, J. M.; Castaño, P. Petcoke-derived functionalized activated carbon as support in a bifunctional catalyst for tire oil hydroprocessing. Fuel Process. Technol. 2016, 144, 239-247.

(7) Zeng, D.; Liu, S.; Gong, W.; Wang, G.; Qiu, J.; Tian, Y. Acid properties of solid acid from petroleum coke by chemical activation and sulfonation. Catal. Commun. 2013, 40, 5-8.

(8) Molina-Sabio, M.; Rodriguez-Reinoso, F. Role of chemical activation in the development of carbon porosity. Colloids Surf., A 2004, 241, 15-25.

(9) Ahmadpour, A.; Do, D. The preparation of active carbons from coal by chemical and physical activation. Carbon 1996, 34, 471-479.

(10) Rodríguez-Reinoso, F. The role of carbon materials in heterogeneous catalysis. Carbon 1998, 36, 159-175.

(11) Auer, E.; Freund, A.; Pietsch, J.; Tacke, T. Carbons as supports for industrial precious metal catalysts. Appl. Catal., A 1998, 173, 259271.

(12) Goncalves, G.; Marques, P. A. A. P.; Granadeiro, C. M.; Nogueira, H. I. S.; Singh, M. K.; Gracio, J. Surface modification of graphene nanosheets with gold nanoparticles: the role of oxygen moieties at graphene surface on gold nucleation and growth. Chem. Mater. 2009, 21, 4796-4802.

(13) Huang, X.; Zhang, F.; Fan, M.; Wang, Y. Catalytic Coal Gasification. Sustainable Catalytic Processes; Saha, B., Fan, M., Wang, J., Eds.; Elsevier: Amsterdam, 2015; Chapter 7, pp 179-199.

(14) Kawashima, D.; Aihara, T.; Kobayashi, Y.; Kyotani, T.; Tomita, A. Preparation of mesoporous carbon from organic polymer/silica nanocomposite. Chem. Mater. 2000, 12, 3397-3401.

(15) Lee, W. J.; Kim, S. D. Catalytic activity of alkali and transition metal salt mixtures for steam-char gasification. Fuel 1995, 74, 13871393.

(16) Wu, M.; Zha, Q.; Qiu, J.; Han, X.; Guo, Y.; Li, Z.; Yuan, A.; Sun, X. Preparation of porous carbons from petroleum coke by different activation methods. Fuel 2005, 84, 1992-1997.

(17) Tomita, A.; Higashiyama, K.; Tamai, Y. Scanning electron microscopic study on the catalytic gasification of coal. Fuel 1981, 60, $103-114$.

(18) Tamai, H.; Kakii, T.; Hirota, Y.; Kumamoto, T.; Yasuda, H. Synthesis of extremely large mesoporous activated carbon and its unique adsorption for giant molecules. Chem. Mater. 1996, 8, 454462.

(19) Hu, Z.; Srinivasan, M. Mesoporous high-surface-area activated carbon. Microporous Mesoporous Mater. 2001, 43, 267-275.

(20) Liang, C.; Ma, W.; Feng, Z.; Li, C. Activated carbon supported bimetallic CoMo carbides synthesized by carbothermal hydrogen reduction. Carbon 2003, 41, 1833-1839.
(21) Wang, H.; Liu, S.; Liu, B.; Montes, V.; Hill, J. M.; Smith, K. J. Carbon and Mo transformations during the synthesis of mesoporous $\mathrm{Mo}_{2} \mathrm{C} /$ carbon catalysts by carbothermal hydrogen reduction. J. Solid State Chem. 2018, 258, 818-824.

(22) Kang, S.; Ye, J.; Chang, J. Recent advances in carbon-based sulfonated catalyst: preparation and application. Int. Rev. Chem. Eng. 2013, 5, 133-144.

(23) Kitano, M.; Arai, K.; Kodama, A.; Kousaka, T.; Nakajima, K.; Hayashi, S.; Hara, M. Preparation of a sulfonated porous carbon catalyst with high specific surface area. Catal. Lett. 2009, 131, 242249.

(24) Geng, H.-Z.; Kim, K. K.; So, K. P.; Lee, Y. S.; Chang, Y.; Lee, Y. $\mathrm{H}$. Effect of acid treatment on carbon nanotube-based flexible transparent conducting films. J. Am. Chem. Soc. 2007, 129, 77587759.

(25) Otake, Y.; Jenkins, R. G. Characterization of oxygen-containing surface complexes created on a microporous carbon by air and nitric acid treatment. Carbon 1993, 31, 109-121.

(26) Afkhami, A.; Madrakian, T.; Karimi, Z. The effect of acid treatment of carbon cloth on the adsorption of nitrite and nitrate ions. J. Hazard. Mater. 2007, 144, 427-431.

(27) Trépanier, M.; Tavasoli, A.; Dalai, A. K.; Abatzoglou, N. Fischer-Tropsch synthesis over carbon nanotubes supported cobalt catalysts in a fixed bed reactor: Influence of acid treatment. Fuel Process. Technol. 2009, 90, 367-374.

(28) Liu, T.; Li, Z.; Li, W.; Shi, C.; Wang, Y. Preparation and characterization of biomass carbon-based solid acid catalyst for the esterification of oleic acid with methanol. Bioresour. Technol. 2013, $133,618-21$.

(29) Shu, Q.; Gao, J.; Nawaz, Z.; Liao, Y.; Wang, D.; Wang, J. Synthesis of biodiesel from waste vegetable oil with large amounts of free fatty acids using a carbon-based solid acid catalyst. Appl. Energy 2010, 87, 2589-2596.

(30) Wigmans, T. Industrial aspects of production and use of activated carbons. Carbon 1989, 27, 13-22.

(31) Keep, C.; Terry, S.; Wells, M. Studies of the nickel-catalyzed hydrogenation of graphite. J. Catal. 1980, 66, 451-462.

(32) Baker, R.; Sherwood, R.; Dumesic, J. Catalytic hydrogenation of graphite by platinum, iridium, and platinum-iridium. J. Catal. 1980, $66,56-64$.

(33) Xia, W.; Wang, Y.; Bergsträßer, R.; Kundu, S.; Muhler, M. Surface characterization of oxygen-functionalized multi-walled carbon nanotubes by high-resolution X-ray photoelectron spectroscopy and temperature-programmed desorption. Appl. Surf. Sci. 2007, 254, 247250.

(34) Dimiev, A. M.; Alemany, L. B.; Tour, J. M. Graphene Oxide. Origin of Acidity, Its Instability in Water, and a New Dynamic Structural Model. ACS Nano 2013, 7, 576-588.

(35) Peters, T. A.; Benes, N. E.; Holmen, A.; Keurentjes, J. T. F. Comparison of commercial solid acid catalysts for the esterification of acetic acid with butanol. Appl. Catal., A 2006, 297, 182-188.

(36) Lee, W.-S.; Kumar, A.; Wang, Z.; Bhan, A. Chemical titration and transient kinetic studies of site requirements in $\mathrm{Mo}_{2} \mathrm{C}$-catalyzed vapor phase anisole hydrodeoxygenation. ACS Catal. 2015, 5, 41044114.

(37) Liew, S. C.; Hill, J. M. Impacts of vanadium and coke deposits on the $\mathrm{CO} 2$ gasification of nickel catalysts supported on activated carbon from petroleum coke. Appl. Catal., A 2015, 504, 420-428.

(38) Liang, C.; Ying, P.; Li, C. Nanostructured $\beta-\mathrm{Mo}_{2} \mathrm{C}$ prepared by carbothermal hydrogen reduction on ultrahigh surface area carbon material. Chem. Mater. 2002, 14, 3148-3151.

(39) Peters, T.; Benes, N.; Holmen, A.; Keurentjes, J. Comparison of commercial solid acid catalysts for the esterification of acetic acid with butanol. Appl. Catal., A 2006, 297, 182-188.

(40) Sepúlveda, J. H.; Yori, J.; Vera, C. Repeated use of supported $\mathrm{H}_{3} \mathrm{PW}_{12} \mathrm{O}_{40}$ catalysts in the liquid phase esterification of acetic acid with butanol. Appl. Catal., A 2005, 288, 18-24. 
(41) Wang, H.; Liu, S.; Smith, K. J. Synthesis and Hydrodeoxygenation Activity of Carbon Supported Molybdenum Carbide and Oxycarbide Catalysts. Energy Fuels 2016, 30, 6039-6049. 